\title{
An Empirical Study on E-Banking Acceptance in the United Arab Emirates (UAE)
}

\author{
Ramona Florentina Rusu ${ }^{1}$ and Kathy Ning Shen ${ }^{2}$ \\ ${ }^{1}$ Jumeirah Group, Dubai, United Arab Emirates \\ ${ }^{2}$ Faculty of Business and Management, University of Wollongong in Dubai, United Arab Emirates
}

\begin{abstract}
While most banks in the UAE have adopted the Internet in providing various services, the understanding of the user acceptance of e-banking services remains limited. Prior studies on ebanking acceptance have been mainly conducted in the western countries. Given the different population and culture in the UAE from the western countries, it is necessary to identify the factors that are more relevant to the context. Built upon the Technology Acceptance Model (TAM), this study examines e-banking acceptance in the context of the UAE. Specific factors were identified, i.e., security, image, convenience and computer self-efficacy, and incorporated into the TAM. The resulting research model was validated with a survey study involving 183 e-banking users and the results provided support for the extended TAM model. Both theoretical and practical implications are discussed.
\end{abstract}

Keywords: Internet banking, TAM, Middle East

\section{Introduction}

Internet has been used to support many traditional banking services, such as opening a deposit account or transferring funds among different accounts. It also enables some new services, such as electronic bill payments and online investment. Banks expect such Internet banking services to reduce operational cost and increase customer satisfaction. However, to reap such anticipated benefits demands a high acceptance rate among consumers. Assessing and understanding customers' intention to use Internet banking has received much interest from both academia and practitioners. The UAE is a culturally diverse country with the highest penetration internet access rate in the Middle East and rated $23^{\text {rd }}$ in the world out of 133 countries by the World Economic Forum's Network Readiness
Index (Department, 2011). Particularly Dubai has invested to become the financial centre in the Gulf region. There are 29 banks operating in Dubai. With increasing competition, banks have increasingly adopted Internet in providing various services. Previous research into internet banking has mainly focused on the adoption of these services in the context of North America and Europe and to a lesser extent in other regions containing a mix of developed and developing countries. Although insightful, the generalization to the other regions where user environment could be very different in terms of computer skills, perception of Internet banking and etc. warrant further investigation.

Thus, built upon the Technology Acceptance Model (TAM) (Davis, 1989), this study aims to identify the factors influencing consumers'

Copyright (C) 2012 Ramona Florentina Rusu and Kathy Ning Shen. This is an open access article distributed under the Creative Commons Attribution License unported 3.0, which permits unrestricted use, distribution, and reproduction in any medium, provided that original work is properly cited. Contact author: Ramona Florentina Rusu E-maill: ramona.ciocan@jumeirah.com 
intention to adopt Internet banking in the UAE and empirically tested their effects. Particularly, four factors were identified to influence consumers' attitude towards Internet banking, i.e., perceived security of using Internet banking, convenience, image and computer self-efficacy. The extended TAM with identified factors was then tested with a survey study involving 183 Internet banking consumers in UAE.

In the next section we present a review of the literature on technology acceptance, based on which we propose a model of customers' intention to adopt internet banking, and formulate the associated research hypotheses. We then discuss the research methodology, and present the findings from the analysis of the empirical data and conclude the paper with discussions of the limitations of the study and further research directions.

\section{Literature Review}

The adoption of information technology systems, including internet banking has been studied through the use of different models throughout the years. In order to understand the reasons behind the decision of customer to use internet banking services or not, most literature researches are based on the Technology Acceptance Model (TAM) (Davis, 1989). The classical Technology Acceptance Model has been a foundation model in understanding a person's decision to utilize technology (Kwon and Wen, 2010, Gefen et al., 2003, Ridings and Gefen, 2000). According to this model, attitude (ATT) refers to an individual's positive or negative feelings about performing a particular behavior. Intention to Use (IU) refers to customers' intention to use, as opposed to their actual use, internet banking services. The model identifies Perceived Usefulness (PU) and Perceived Ease of Use (PEOU) as key factors that influence acceptance of certain technologies. PEOU is defined by Davis as "the degree to which a person believes that using a particular system would be free of effort". (Davis, 1989)PU is defined by Davis as "the degree to which a person believes that using a particular system would enhance his job performance" (Davis, 1989).

Numerous researches have been conducted after to validate this model by other researchers (Venkatesh and Bala, 2008). Some of the shortfalls of the model refer to the fact that the model only focuses on the technological aspects of internet banking adoption decision and neglects other parameters like social and psychological. (Gounaris and Koritos, 2008) Two other theoretical frameworks that address these issues are the Diffusion of Innovations suggested by Rogers (Rogers, 2003) and Perceived Characteristics of the Innovations suggested by Moore and Benbasat. (Moore and Benbasat, 1996) However, there has been very little evidence in literature that these two models would be more appropriate to study the factors that influence the adoption of internet banking by consumers than TAM which is the main reason why TAM has been chosen as the baseline model in this study.

Looking at the UAE economy, one of the biggest beneficiaries of the strong economic growth was the banking sector. Due to relatively low interest rate environment, high oil prices and a growing economy, this sector in the UAE has been growing by around 30\% year by year in the last 5 years. At the end of 2009 , there were 52 banks in the country, from which 24 were UAE banks and 28 foreign banks. The number of branches has increased by $10 \%$ compared to 2008 , reaching a number of 948 (includes head offices, banking service units, branches, etc) as per the UAE Central Bank report. The number of banks in the UAE compared to the total population is one of the highest in the world (Fatma, 2010).

Limited evidence of in-depth research of the acceptance of the internet banking in the UAE has been identified in the literature. Two studies were identified which analyzed the internet banking channels and service preference of banking consumers in the UAE 
and identified the factors that influence the intention to adopt or to continue the use of internet banking and are significant for customer satisfaction (Awamleh and Fernandes, 2006) and (Awamleh and Fernandes, 2005). Another study was identified which investigated the extent and the quality of electronic banking in the UAE. (Bruce Budd and Daniel Budd, 2007) All three studies concluded that the financial sector in the UAE is not yet very well developed and internet banking is yet to be properly utilized as a real added value tool to improve customer relationship and to attain cost advantage. In regards to the factors that have an influence on the adoption of internet banking, the TAM model was utilized in one of the study together with additional variables like perceived risk, image, computer self-efficacy and convenience. The studies revealed that convenience and security have a significant impact on satisfaction and the higher the perceived risk the lower the intention to adopt.

Our study extends the research into the factors that influence the adoption of internet banking among banking consumers in the UAE and the current level of adoption of this channel.

\section{Hypothesis Development}

In this study, we extended TAM with some additional variables which were considered important in some literature studies and we considered as important for the UAE market. The theoretical model is graphically presented in Fig.1.

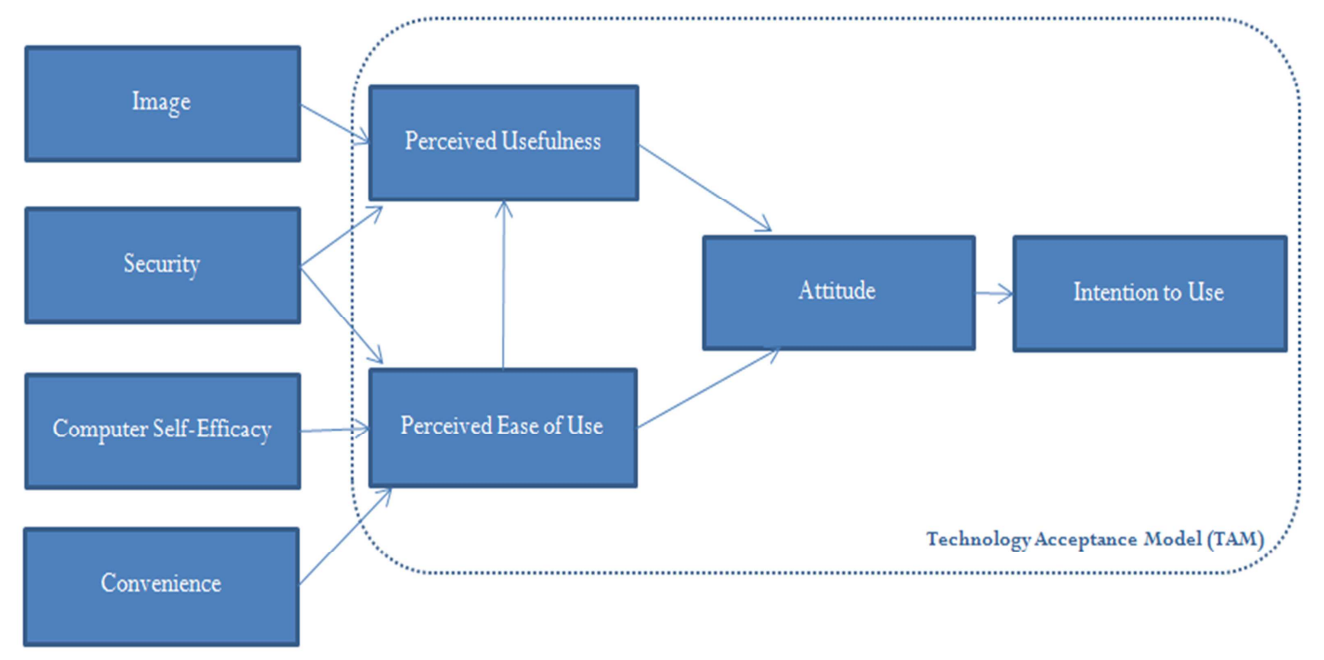

Fig 1. Conceptual Model Extending the Classical TAM with Image, Security, Computer SelfEfficacy and Convenience

Security (SEC) refers to the protection of information and systems from unauthorized intrusions and is linked to the perceived risk that the customers may fear that an unauthorized party will gain access to their online account and their online transactions. It was defined by Salisbury et al. as "the extent to which one believes that the World Wide Web is secure for transmitting sensitive information." (Salisbury et al., 2001) A survey conducted by White and Nteli with UK consumers identified the security of a bank's website as the most important attribute of internet banking service quality. (Polasik and Wisniewski, 2009) Overall, the literature sustains the fact that security concerns have a negative impact on the adoption of internet banking. (Polasik and Wisniewski, 2009) 
Security is a very relevant factor in an environment like the UAE where the majority of population is expatriate who would regularly make fund transfers to their accounts in their home countries and would be probably looking to use internet banking for that purpose. The risk of errors in online transfer is definitely something to consider when considering whether to use that channel or not. Therefore, we hypothesize that:

\section{H1: SEC is Positively Related to PU and PEOU.}

Image (IMG) refers to "the degree to which potential users perceive the usage of a technologically based innovation as adding prestige to their social icon" (Gounaris and Koritos, 2008). It is another variable relevant to perceived usefulness as being luxury and the prestige have been one of predominant characteristics of consumer markets in UAE in general. Similarly, when using Internet banking is perceived as prestigious or unique, consumers will be more motivated to adopt Internet banking services. Therefore, we hypothesize that:

\section{H2: IMG is Positively Related to PU.}

Computer self-efficacy (CSE) is an individual's belief about his or her ability to successfully use a computer or a technological service to accomplish a specific task. (Compeau and Higgins, 1995) This factor has also been cited, along with trust, as critical in the literature in determining an individual's intention to use an information system. There is empirical evidence shown in previous studies on the effect of computer self-efficacy on perceived usefulness and perceived ease of use that has been documented in studies as the ones published by Agarwal et al., 2000; Venkatesh, 2000; Venkatesh and Davis, 1996; Igbaria and Livari, 1995 (Amin, 2007). The UAE is a multicultural country, with people from different nationalities and from all different levels living and working here. Being able to use a computer and complete certain tasks with the help of a computer is very important in such an environment and could influence a lot the decisions that different categories of people take whether to use technology or not to complete banking transactions. Therefore, we hypothesize that:

\section{H3: CSE is Positively Related to PEOU.}

Convenience (CNV) refers to the possibility of accessing the services of the bank anywhere at any time (Awamleh and Fernandes, 2005).This variable has not been used in previous studies but it is viewed as a very important advantage of internet banking especially in today's world when everybody wants to be able to have access to services anywhere at any time. In the UAE we considered that this is a very important factor for the residents of this country, as they are very much hooked on convenience. The culture of the country is centered on convenience, the same way it is on image and that is the reason why we introduced this variable in our model to test it. Therefore, we hypothesize that:

\section{H4: CNV is Positively Related to PEOU.}

\section{Research Method}

The hypotheses were tested with an online survey involving 183 bank customers residing in the UAE. The descriptive statistics of the respondents' demographic characteristics were analyzed and presented in Table 1. 
Table 1: Demographic of Respondents

\begin{tabular}{|l|c|c|l|c|l|}
\hline & Frequency & $\mathbf{9}$ & & Frequency & $\mathbf{\%}$ \\
\hline Sex & & & Nationality & & \\
\hline Male & 114 & $62 \%$ & North America & 11 & $6 \%$ \\
\hline Female & 69 & $38 \%$ & Europe & 30 & $16 \%$ \\
\hline Age & & & Middle East \& North Africa & 63 & $34 \%$ \\
\hline 18 to 25 & 39 & $21 \%$ & Asia \& Australia & 55 & $30 \%$ \\
\hline 26 to 30 & 69 & $38 \%$ & Other & 2 & $1 \%$ \\
\hline 36 to 40 & 16 & $9 \%$ & Job level & & \\
\hline$>40$ & 15 & $9 \%$ & Non-employed & 23 & $13 \%$ \\
\hline Monthly Income (AED) & & & Self-employed & 9 & $5 \%$ \\
\hline 0 to 5,000 & 50 & $27 \%$ & Front line employee & 35 & $19 \%$ \\
\hline 5,000 to 10,000 & 39 & $21 \%$ & Middle Management & 68 & $37 \%$ \\
\hline 10,000 to 25,000 & 69 & $38 \%$ & Senior Management & 21 & $11 \%$ \\
\hline 25,000 to 50,000 & 17 & $9 \%$ & Education Level & 21 & $11 \%$ \\
\hline Over 50,000 & 2 & $1 \%$ & Secondary & 124 & $68 \%$ \\
\hline Do not wish to disclose & 6 & $3 \%$ & College/University & 38 & $21 \%$ \\
\hline & & & Master/PHD & & \\
\hline
\end{tabular}

All the 183 respondents had internet access, the majority (60\%) accessing it from home, with the rest accessing it from their work areas. The majority of the respondents were male $(62 \%)$, below 35 years old, earning 10,000 to 25,000 Dhs, (38\%), having achieved a college or university degree, (68\%), and occupying middle management roles in their organizations. From the 183 respondents, $50 \%$ evaluated their computer skills knowledge as advanced and $37 \%$ as average. The predominant nationalities were from Middle East and North Africa and Asia and Australia with $64 \%$ of the respondents falling in those categories.

Variables were measured with the 5-point Likert scales developed and validated in prior studies. Particularly, we adapted the measures for perceived usefulness, perceived ease of use, attitude, intention of use from (Davis, 1989), image, from (Awamleh and Fernandes, 2006), security, from (Cheng et al., 2006), computer self-efficacy, from (Compeau and Higgins, 1995) and convenience, from (Polatoglu and Ekin, 2001).

\section{Data Analysis}

The analysis of the data was done using Partial Least Square (PLS). The PLS analysis indicates how well the measures relate to each construct and whether the hypothesized relationship at the theoretical level are empirically true. PLS-Graph was used to perform the analysis. In evaluating the measurement model, path loadings of 0.7 or higher were considered as acceptable. For the evaluation of the structural model (hypothesized links) the bootstrap resampling procedure (Cotterman and Senn, 1992) was applied to test the significance of the paths coefficients. In assessing the internal consistency, we looked at the composite reliability measures $(\rho)$ developed by Werts et al. (1974).

\section{Results and Discussion}

Table 2 presents the loading, standard error and $t$-statistic of the items to their respective constructs. For all constructs, most of the items had reasonably high loadings (i.e. above 0.70 ) with the majority over 0.80 , 
therefore demonstrating convergent validity (see Table 2). Furthermore, all items were found to be significant (almost all at the 0.01 level). The composite reliability measures (see $\rho$ in Table 2) provided additional support for the reliability and the convergent validity.

Table 2: Loadings, Significance and Composite Reliability ( $\rho)$

\begin{tabular}{|c|c|c|c|c|}
\hline Construct & Measurement Item & Loading & Standard & t-Statistic \\
\hline \multirow{3}{*}{$\begin{array}{l}\text { Attitude } \\
\rho=0.80\end{array}$} & Item 1 & 0.88 & 0.04 & 24.14 \\
\hline & Item 2 & 0.88 & 0.03 & 26.96 \\
\hline & Item 3 & 0.91 & 0.03 & 35.16 \\
\hline \multirow{4}{*}{$\begin{array}{l}\text { Convenience } \\
\qquad \rho=0.71\end{array}$} & Item 1 & 0.90 & 0.02 & 36.06 \\
\hline & Item 2 & 0.86 & 0.06 & 13.83 \\
\hline & Item 3 & 0.92 & 0.02 & 48.24 \\
\hline & Item 4 & 0.68 & 0.08 & 8.09 \\
\hline \multirow{3}{*}{$\begin{array}{l}\text { Computer Self-Efficacy } \\
\qquad \rho=0.74\end{array}$} & Item 1 & 0.87 & 0.03 & 25.87 \\
\hline & Item 2 & 0.87 & 0.03 & 26.72 \\
\hline & Item 3 & 0.83 & 0.05 & 15.41 \\
\hline \multirow{2}{*}{$\begin{array}{l}\text { Image } \\
\rho=0.92\end{array}$} & Item 1 & 0.95 & 0.05 & 20.62 \\
\hline & Item 2 & 0.95 & 0.09 & 11.36 \\
\hline \multirow{2}{*}{$\begin{array}{l}\text { Intention } \\
\rho=0.84\end{array}$} & Item 1 & 0.93 & 0.03 & 35.00 \\
\hline & Item 2 & 0.91 & 0.03 & 35.60 \\
\hline \multirow{3}{*}{$\begin{array}{l}\text { Perceived Ease of Use } \\
\qquad \rho=0.76\end{array}$} & Item 1 & 0.80 & 0.06 & 13.28 \\
\hline & Item 2 & 0.90 & 0.03 & 34.28 \\
\hline & Item 3 & 0.89 & 0.03 & 35.62 \\
\hline \multirow{3}{*}{$\begin{array}{l}\text { Perceived Usefulness } \\
\qquad \rho=0.85\end{array}$} & Item 1 & 0.92 & 0.02 & 42.21 \\
\hline & Item 2 & 0.93 & 0.02 & 58.17 \\
\hline & Item 3 & 0.91 & 0.02 & 40.02 \\
\hline \multirow{4}{*}{$\begin{array}{l}\text { Security } \\
\rho=0.74\end{array}$} & Item 1 & 0.66 & 0.09 & 7.35 \\
\hline & Item 2 & 0.92 & 0.02 & 55.11 \\
\hline & Item 3 & 0.91 & 0.02 & 43.07 \\
\hline & Item 4 & 0.90 & 0.03 & 28.08 \\
\hline
\end{tabular}

As indicated in Table 3, the value of the squared correlation of the constructs were all smaller than the average variance extracted (i.e. indicated by the diagonal) of their respective constructs demonstrated that the discriminate validity of the study was guaranteed. 
Table 3: Correlation Matrix

\begin{tabular}{|c|c|c|c|c|c|c|c|c|}
\hline & ATT & CNV & CSE & IMG & IU & PEU & PU & SEC \\
\hline Attitude & $\mathbf{0 . 9 0}$ & & & & & & & \\
\hline Convenience & 0.71 & $\mathbf{0 . 8 4}$ & & & & & & \\
\hline Computer Self- & 0.58 & 0.44 & $\mathbf{0 . 8 6}$ & & & & & \\
\hline Image & 0.29 & 0.26 & 0.31 & $\mathbf{0 . 9 6}$ & & & & \\
\hline Intention & 0.78 & 0.59 & 0.51 & 0.37 & $\mathbf{0 . 9 2}$ & & & \\
\hline Perceived Ease of Use & 0.72 & 0.57 & 0.68 & 0.24 & 0.61 & $\mathbf{0 . 8 7}$ & & \\
\hline Perceived Usefulness & 0.80 & 0.58 & 0.52 & 0.20 & 0.61 & 0.75 & $\mathbf{0 . 9 2}$ & \\
\hline Security & 0.51 & 0.36 & 0.55 & 0.35 & 0.58 & 0.49 & 0.45 & $\mathbf{0 . 8 6}$ \\
\hline
\end{tabular}

Structural model of PLS was tested on the basis of path strengths and variance explained (see Figure 2). As indicated by the significant path coefficients and more than $50 \%$ variance of attitude and intention explained by PEU and PU, TAM was fully supported by the empirical data. Moreover, computer self-efficacy and convenience were found to be significant in predicting PEU. Together, they explained $57 \%$ variance of PEU, supporting H3\&4. The other two variables, i.e., image and security, were not significant. One plausible explanation might be that the image, even though is an important cultural aspect in the UAE, may matter more for hedonic and/or luxury products or services, but is not necessarily related to the evaluation of Internet banking service that is more utilitarian.. Security does remain an important aspect for the adoption of information systems as shown by so many other studies and this result demonstrates that this variable does not influence how useful people find internet banking or how easy to use they believe it to be. We then conducted an ad hoc analysis which reported a significant direct link between security and attitude $(\beta=0.154 ; t=2.765)$. This result suggested that the security was an important source for attitude towards Internet banking and its effect was not mediated through TAM variables.

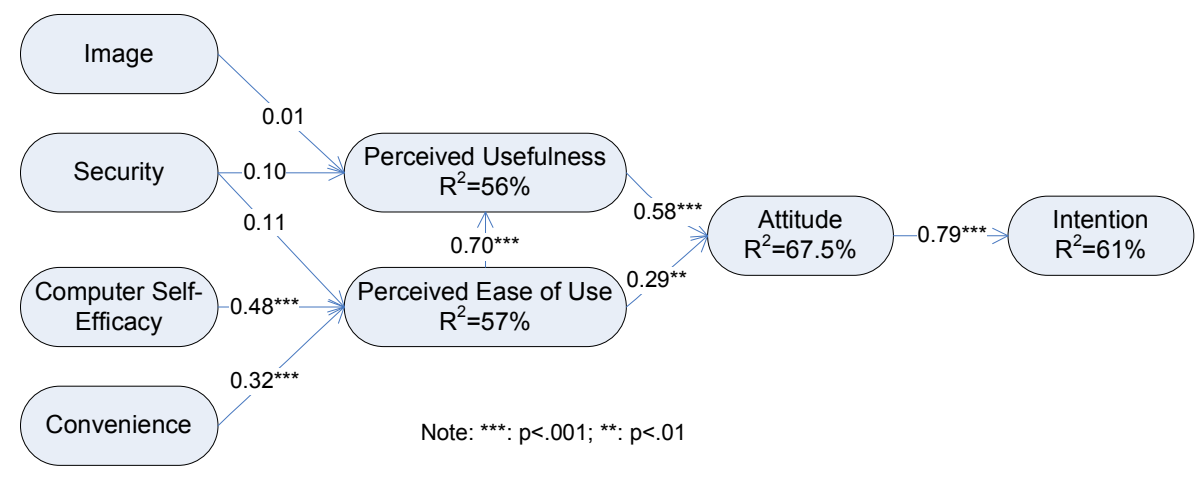

Fig 2. Result of PLS Analyses

\section{Conclusions \& Implications}

The findings of the empirical study provide support for the TAM theoretical model, extended with convenience and computer self-efficacy. The results support the view that Computer Self-Efficacy and Convenience are important factors that determine the Perceived Ease of Use for internet banking customers in the UAE, supporting hypothesis 
$\mathrm{H} 3$ and H4. In the same time, Security has been identified as not having a positive impact on either Perceived Usefulness or Perceived Ease of Use as per H1 hypothesis, while Image has been identified as not having a positive impact on Perceived Usefulness in line with $\mathrm{H} 2$ hypothesis. This provides support for further studies to investigate the relationship of Security with Attitude and Intention to Use, as this variable remains an important factor that affects the possible adoption of this channel. "I am concerned because of security" was identified as the most important reason by the 89 non-users of internet banking for not currently using this channel who responded to our survey.

Currently all the UAE banks are offering internet banking to their customers, each at a different level, but the majority are giving access to the most important services that are used frequently by all the users: viewing statements and account balances, paying bills and credit cards. Between the top 10 banks identified as the most used by the respondents, only 2 were international banks, the rest being local or regional banks, even though the most used by the respondents was an international one (HSBC).

Recommendations for banks are to increase the awareness around the measures taken to ensure the security of the system in their campaigns to encourage customers to use internet banking, sending e-mails to customers to confirm online transactions, creating some sort of loyalty programs for internet banking users maybe similar to the ones the airlines or hotels use, addressing especially the customers that are working with that bank for a long period of time and are loyal to them. This will definitely increase the chances of a higher use of internet banking as customers seem to be open to technology, have access to internet and are computer knowledgeable.

Future research in this area can focus on investigating the launch on a specific new internet banking product/service on the market and the level of adoption of the banking consumers. The study could be conducted at early stages of adoption using the same model to understand in more details the factors that could determine the users to adopt a new internet banking service. This way the model could be further refined and the bank could make any adjustments to the product or service at early stage and ensure successful implementation on the market.

\section{References}

Amin, H. (2007). "Internet Banking Adoption Among Young Intellectuals," The Journal of Internet Banking and Commerce, 12, 1-13.

Awamleh, R. \& Fernandes, C. (2005). 'Internet Banking: An Empirical Investigation into the Extent of Adoption by Banks and the Determinants of Customer Satisfaction in the United Arab Emirates,' The Journal of Internet Banking and Commerce, 10.

Awamleh, R. \& Fernandes, C. (2006). "Diffusion of Internet Banking amongst Educated Consumers in a High Income nonOECD Country," Journal of Internet Banking and Commerce, 11, 1-15.

Bruce Budd, D. \& Daniel Budd, B. (2007). 'A Preliminary Empirical Investigation of 'Brickto-Click' Banking Presence in the United Arab Emirates,' Journal of Internet Banking and Commerce, 12, 1-7.

Cheng, T. C. E., Lama, D. Y. C. \& Yeunga, A. C. L. (2006). "Adoption of Internet Banking: An Empirical Study in Hong Kong," Decision Support Systems, 42, 1558-1572.

Compeau, D. R. \& Higgins, C. A. (1995). "Computer Self-Efficacy: Development of a Measure and Initial Test," MIS Quarterly, 19 (Jun), 189-211.

Cotterman, W. \& Senn, J. (1992). Challenges and Strategies for Research in Systems Development, John Wiley \& Sons, Chichester 
9 Journal of Electronic Banking Systems

Davis, F. D. (1989). "Perceived Usefulness, Perceived Ease of Use, and User Acceptance of Information Technology," MIS Quarterly, 13 (Sep), 319-340.

Economic Research Department (2011). 'Challenges and Prospects for UAE telecom sector'. Dubai Chamber Economist.

Fatma, S. (2010), "Banking Industry in UAE," [Online], [Retrieved November 2010], http://www.slideshare.net/sabafatma/banki ng-industry-in-

uae?src=related_normal\&rel=612831

Gefen, D., Karahanna, E. \& Straub, D. W. (2003). "Trust and TAM in Online Shopping: An Integrated Model," MIS Quarterly, 27, 5190.

Gounaris, S. \& Koritos, C. (2008). "Investigating the Drivers of Internet Banking Adoption Decision: A Comparison of Three Alternative Frameworks," International Journal of Bank Marketing, 26, 282-304.

Kwon, 0. \& Wen, Y. (2010). "An Empirical Study of the Factors Affecting Social Network Service Use," Computers in Human Behavior.

Moore, G. C. \& Benbasat, I. (1996). "Integrating Diffusion of Innovations and Theory of Reasoned Action Models to Predict Utilization of Information Technology by End-Users," Diffusion and Adoption of Information Technology, 132-146.

Polasik, M. \& Wisniewski, T. P. (2009). "Empirical Analysis of Internet Banking Adoption in Poland," International Journal of Bank Marketing, 27, 32-52.

Polatoglu, V. N. \& Ekin, S. (2001). "An Empirical Investigation of the Turkish Consumers' Acceptance of Internet Banking Services," The International Journal of Bank Marketing, 19, 156 - 165.

Ridings, C. \& Gefen, D. (2000). "Applying TAM to A Parallel Systems Conversion Strategy,"
Journal of Information Technology Theory \& Application, 2

Rogers, E. M. (2003). Diffusion of Innovations, The Free Press, New York, NY,

Salisbury, W. D., Pearson, R. A., Pearson, A. W. \& Miller, D. W. (2001). "Perceived Security and World Wide Web Purchase Intention," Industrial Management and Data Systems, 101, 165-176.

Venkatesh, V. \& Bala, H. (2008). "Technology Acceptance Model 3 and a Research Agenda on Interventions," Decision Sciences, 39, 273315.

Werts, C. E., Linn, R. L. \& Joreskog, K. G. (1974). "Intraclass Reliability Estimates: Testing Structural Assumptions," Educational and Psychological Measurement, 34, 25-33. 